\title{
Twin grasper-assisted endoscopic mucosa-inverting closure for large perforations after endoscopic full-thickness resection: a new endoscopic technique
}

There is no commonly accepted technique for closure of large perforations (diameter $>2 \mathrm{~cm}$ ) after endoscopic fullthickness resection (EFTR), owing to inevitable limitations of each technique [1]. Gastrointestinal full-thickness defects can be closed by closing the mucosal layer only [2-4]. Here, we describe a new technique for closing large perforations. This technique uses through-thescope (TTS) clips, which are widely used in practice, to close the mucosa in an inverted fashion with assistance of a twin grasper, thus overcoming the limitations of TTS clips. This technique may be a better choice for repair of large perforations after EFTR and can be easily adopted in local hospitals.

The procedural steps are shown in a porcine stomach with a 2-cm iatrogenic perforation created by EFTR ( $\triangleright$ Video 1 ). A twin grasper (Ovesco, Tübingen, Germany) was inserted into one of the working channels of an endoscope with two working channels (Olympus, Tokyo, Japan). Then, one of the arms was opened to grasp one side of the seromuscular layer of the perforation ( $\triangleright$ Fig. $\mathbf{1}$ a), and the other arm was opened to clamp the contralateral seromuscular layer. Thus, the mucosal layers were inverted and

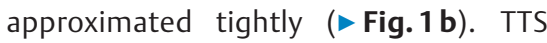
clips (Micro-Tech, Nanjing, China) were then inserted into another working channel to close the mucosa near to the twin grasper ( Fig. 1 c). Finally, we completed the closure by deploying further TTS clips from the midpoint of the incision to the bilateral incision margins (- Fig. $\mathbf{1 d}$ ). In this way, the inverted mucosal layer was closed, with the muscularis mucosa in tight apposition ( $>$ Fig. 2 ). Tightness of the closure was confirmed by insufflating carbon dioxide into the stomach and flushing water onto the serosal surface of the perforation; no running bubbles were observed.

Endoscopy_UCTN_Code_CPL_1AL_2AG

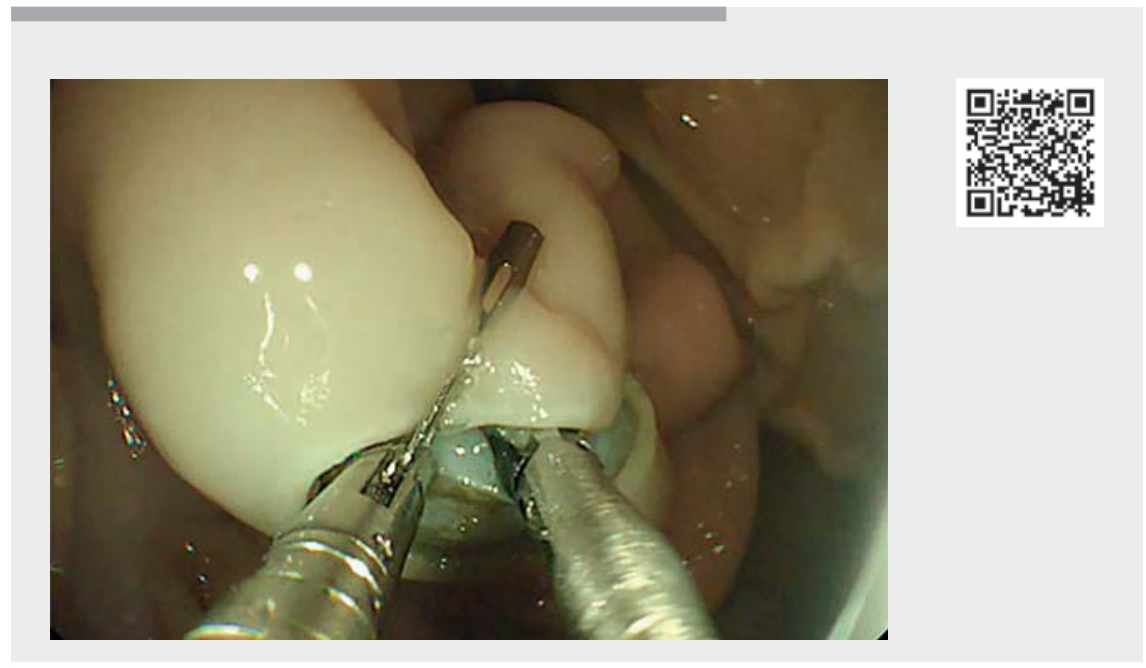

Video 1 Closure of a full-thickness perforation, about $2 \mathrm{~cm}$ in diameter, using the twin grasper-assisted endoscopic mucosa-inverting closure technique.
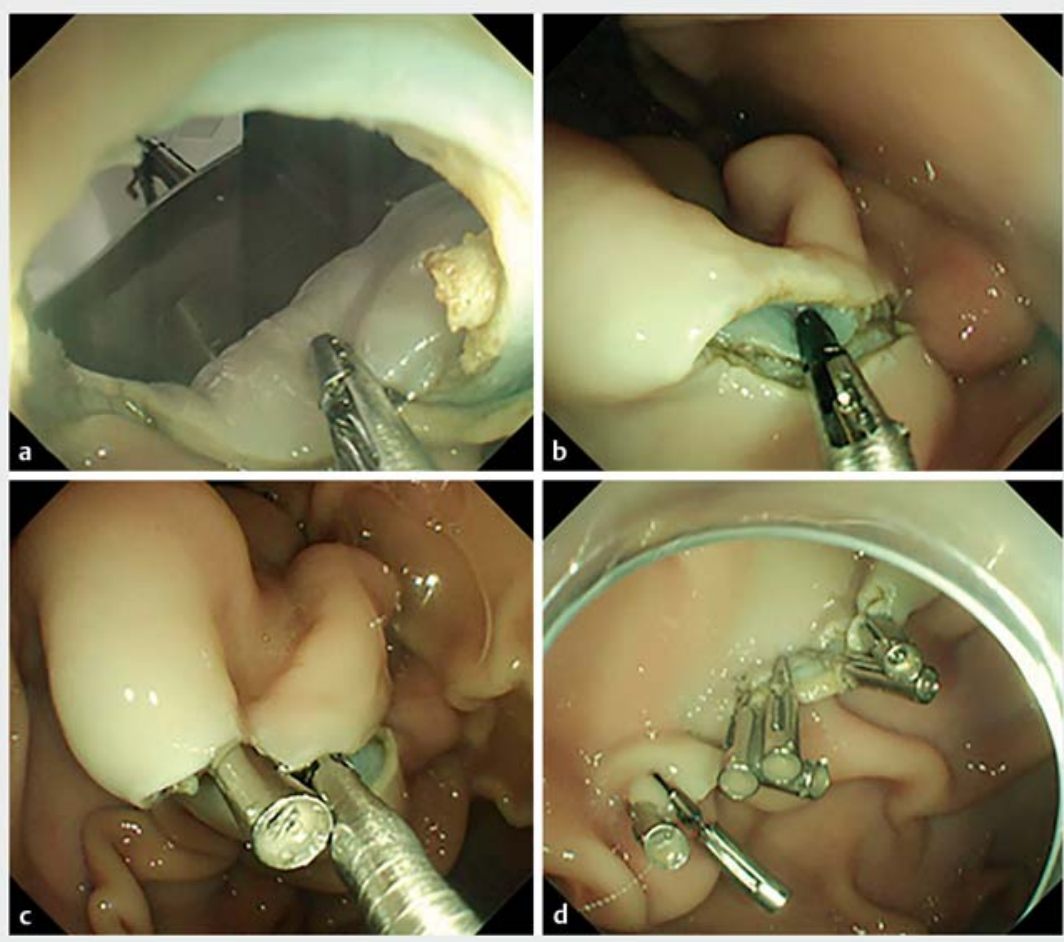

Fig. 1 Endoscopic images. a The twin grasper clamped one side of the seromuscular layer. b The twin grasper approximated the seromuscular layers. c The inverted mucosal layers were closed by metal clips. $\mathbf{d}$ Complete closure of the perforation. 


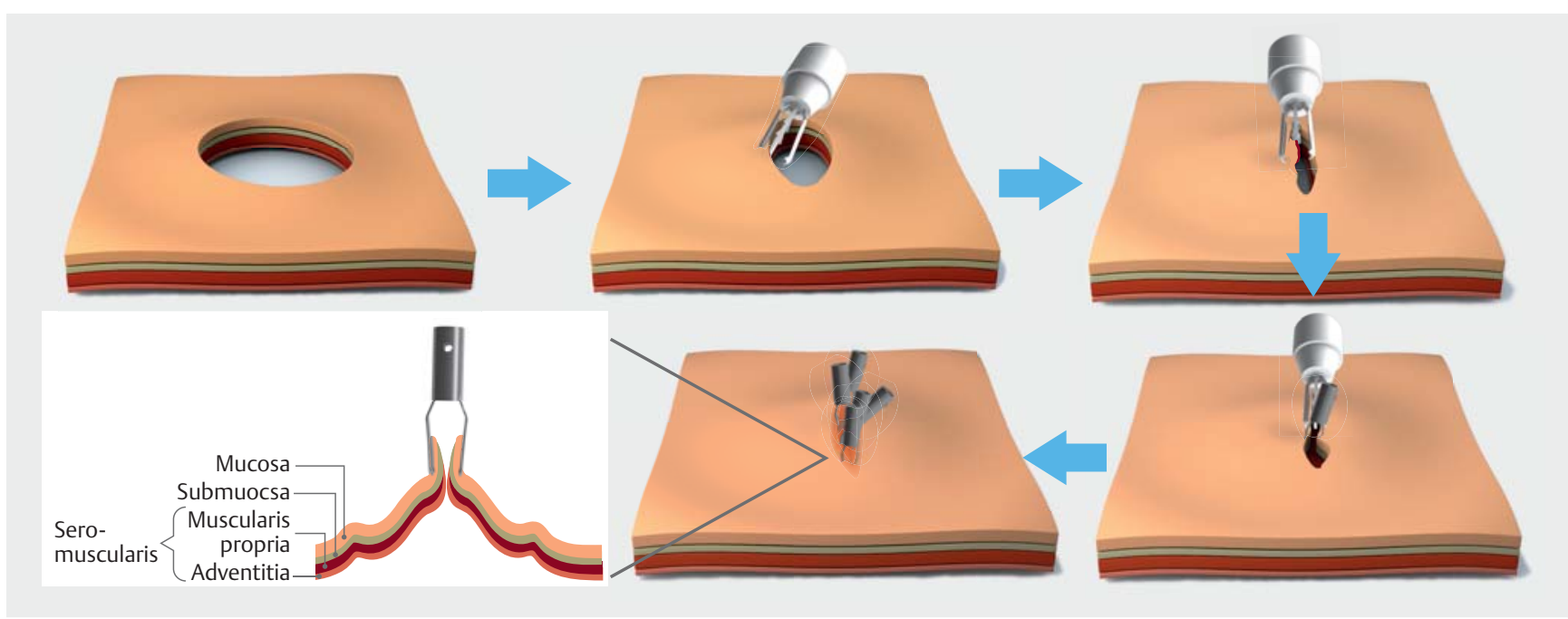

Fig. 2 Schematic diagram of the new technique. After creation of a large perforation by endoscopic full-thickness resection, a twin grasper was used to grasp one side of the seromuscular layer, followed by the contralateral side, thus approximating the mucosal layers. A through-thescope clip was then used to close the inverted mucosal layers, providing good conditions for mucosal healing.

\section{Competing interests}

The authors declare that they have no conflict of interest.

The authors

Qinbo Cai ${ }^{1,2^{*}}$, Lele Zhang ${ }^{1,2^{*}}$, Wentong Lan ${ }^{3}$, Yuan Lin ${ }^{4}$, Minxuan Shen ${ }^{1,2}$, Xun Hou' ${ }^{1,2}$,

\section{Dongjie Yang ${ }^{1,2}$}

1 Center for Gastrointestinal Surgery, The First Affiliated Hospital of Sun Yat-sen University, Guangzhou, China

2 Center for Diagnosis and Treatment of Gastric Cancer, Sun Yat-sen University, Guangzhou, China

3 Department of Endoscopy, The First Affiliated Hospital of Sun Yat-sen University, Guangzhou, China

4 Department of Pathology, The First Affiliated Hospital of Sun Yat-sen University, Guangzhou, China

\section{Corresponding author}

\section{Dongjie Yang, MD, PhD}

Center for Gastrointestinal Surgery, The First Affiliated Hospital, Sun Yat-sen University, No. 58 Zhongshan 2nd Road, Guangzhou, Guangdong Province 510080, P. R. China ydongj@mail.sysu.edu.cn

\section{References}

[1] de Moura DTH, Sachdev AH, Thompson CC. Endoscopic full-thickness defects and closure techniques. Curr Treat Options Gastroenterol 2018; 16: 386-405

[2] Binmoeller KF, Grimm H, Soehendra N. Endoscopic closure of a perforation using metallic clips after snare excision of a gastric leiomyoma. Gastrointest Endosc 1993; 39: $172-174$

[3] Raymer GS, Sadana A, Campbell DB et al. Endoscopic clip application as an adjunct to closure of mature esophageal perforation with fistulae. Clin Gastroenterol Hepatol 2003; 1: 44-50

[4] Raju GS. Endoscopic clip closure of gastrointestinal perforations, fistulae, and leaks. Dig Endosc 2014; 26: 95-104

\section{Bibliography}

Endoscopy 2022; 54: E576-E577

DOI 10.1055/a-1695-3014

ISSN 0013-726X

published online 21.12.2021

(c) 2021. Thieme. All rights reserved.

Georg Thieme Verlag KG, Rüdigerstraße 14,

70469 Stuttgart, Germany

\section{ENDOSCOPY E-VIDEOS}

https://eref.thieme.de/e-videos

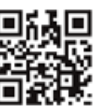

Endoscopy E-Videos is an open access online section, reporting on interesting cases and new techniques in gastroenterological endoscopy. All papers include a high quality video and all contributions are freely accessible online. Processing charges apply (currently EUR 375), discounts and wavers acc. to HINARI are available.

This section has its own submission website at

https://mc.manuscriptcentral.com/e-videos

\footnotetext{
* These authors contributed equally to this work.
} 